\title{
Unusual Relation of the Median Nerve with the Accessory Head of the Biceps Brachii Muscle: An Original Case Report
}

\author{
Una Rara Relación del Nervio Mediano con la Cabeza Accesoria del Músculo Bíceps Braquial: \\ Reporte de Caso
}

"Nuket Mas; "Can Pelin; ** Ragıba Zagyapan \& ***Hakan Bahar

MAS, N.; PELIN, C.; ZAGYAPAN, R. \& BAHAR, H. Unusual relation of the median nerve with the accessory head of the biceps brachii muscle: An original case report. Int. J. Morphol., 24(4):561-564, 2006.

SUMMARY: During the laboratory dissection of the brachial region and the arm, an abnormal relation of median nerve with the accessory head of biceps brachii muscle has been observed unilaterally on the right upper limb of a male cadaver. Whereas the short and long heads have their normal origin, additional-excess third head originated from the anteromedial surface of the superior part of the humerus. Some fibers of this accessory head on the medial side arise from the deep fascia surrounding the brachialis muscle. The fibers then cross the median nerve superficially before joining the third head which has inserted into a common tendon together with the long and short heads.

To have information of such variations is of importance either for anatomists or clinicians especially for plastic surgeons in flap surgery.

KEY WORDS: Biceps brachii muscle; Accessory head; Median nerve; Anatomical variations.

\section{INTRODUCTION}

The biceps brachii is a muscle with two heads in the flexor compartment of the arm. Short one arises from the tip of coracoid process and, the long one from the supraglenoid tubercle of scapula. The tendon of the long head crosses the head of humerus within the capsule of the shoulder joint and emerges from the joint surrounded by a synovial sheath, and descends on the humerus lying in the bicipital groove. The two heads of the muscle fuse in the middle of the arm forming a common tendon and inserts on the radial tuberosity and into the deep fascia on the medial aspect of the forearm by an aponeurotic band named bicipital aponeurosis (also called lacertus fibrosis). The muscle is the prime supinator of the forearm and a powerful flexor of the elbow joint as well. It is also a week flexor of the shoulder joint. The biceps brachii muscle is innervated by the musculocutaneus nerve (Williams et al., 1989: Snell, 2004).

Variations of biceps brachii muscle are common and reported by several authors (Kosugi et al., 1992; Asvat et al., 1993; Jakubowicz \& Ratajczak, 2000; Rodriguez-
Niedenführ et al., 2003). It is well known that a third head may extend from the superomedial part of the brachilis to the bicipital aponeurosis and medial side of the tendon in 10 $\%$ of the cases (Williams et al.).

In the present case an accessory head of biceps brachii muscle and its abnormal relation with median nerve had been studied.

\section{CASE REPORT}

During a routine dissection of a formalin fixed 37 years old male cadaver for student training a three headed biceps brachii muscle was observed on the right side unilaterally. The accessory head lying over the brachialis muscle was originated from the anteromedial surface of humeral shaft, just from the lateral of brachialis muscle insertion and inserted into the posterior aspect of the common biceps

* M.D., Ph.D. Baskent Universitiy Faculty of Medicine Department of Anatomy, 06530 Baglica - Etimesgut Ankara Turkey.

** Ph.D. Baskent Universitiy Faculty of Medicine Department of Anatomy, 06530 Baglica - Etimesgut Ankara Turkey.

**** M.D. Baskent Universitiy Faculty of Medicine Department of Anatomy, 06530 Baglica - Etimesgut Ankara Turkey. 
tendon (Fig. 1). Some fibers of this accessory head on the medial side arose from the deep fascia surrounding the brachialis and crossed the median nerve superficially before joining the third head (Fig 2). After piercing the accessory head the median nerve descends over the brachialis muscle and enters to the forearm passing between the two heads of

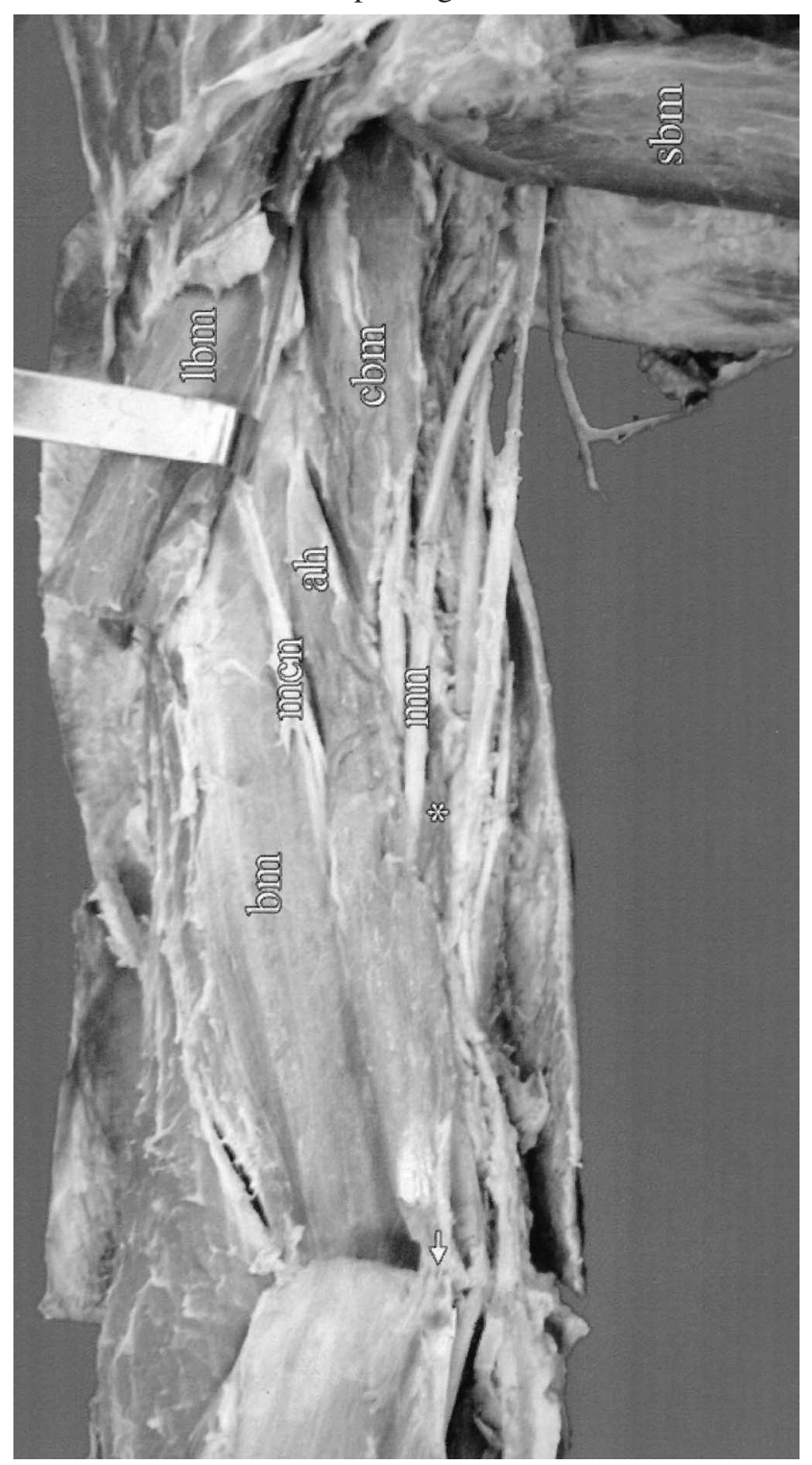

Fig. 1. On the right side, biceps brachii is cut; long and short heads are reflected keeping the accessory head intact. The musculocutaneous nerve is pulled laterally. The accessory head of biceps brachii originates form the anteromedial surface of humerus, from the lateral side of the insertion of cracobrachialis muscle and inserts into the posterior aspect of the common biceps tendon. cbm: Coracobrachialis muscle, lbm: Long head of biceps brachii, sbm: Short head of biceps brachii, ah: Accessory head of biceps brachii, *: Medial fibers of the accessory head originating from the deep fascia of brachialis muscle, $\neq$ : Common tendon of biceps brachii, bbm: Biceps brachii muscle, bm: Brachialis muscle, mn: Median nerve. pronator teres in its usual course. This accessory head also inserted in to the common tendon with the long and short heads. It was observed that the accessory head was innervated by the muscular branches of musculocutaneous nerve as the main two heads. The vascular supply of this third head was also the brachial artery.

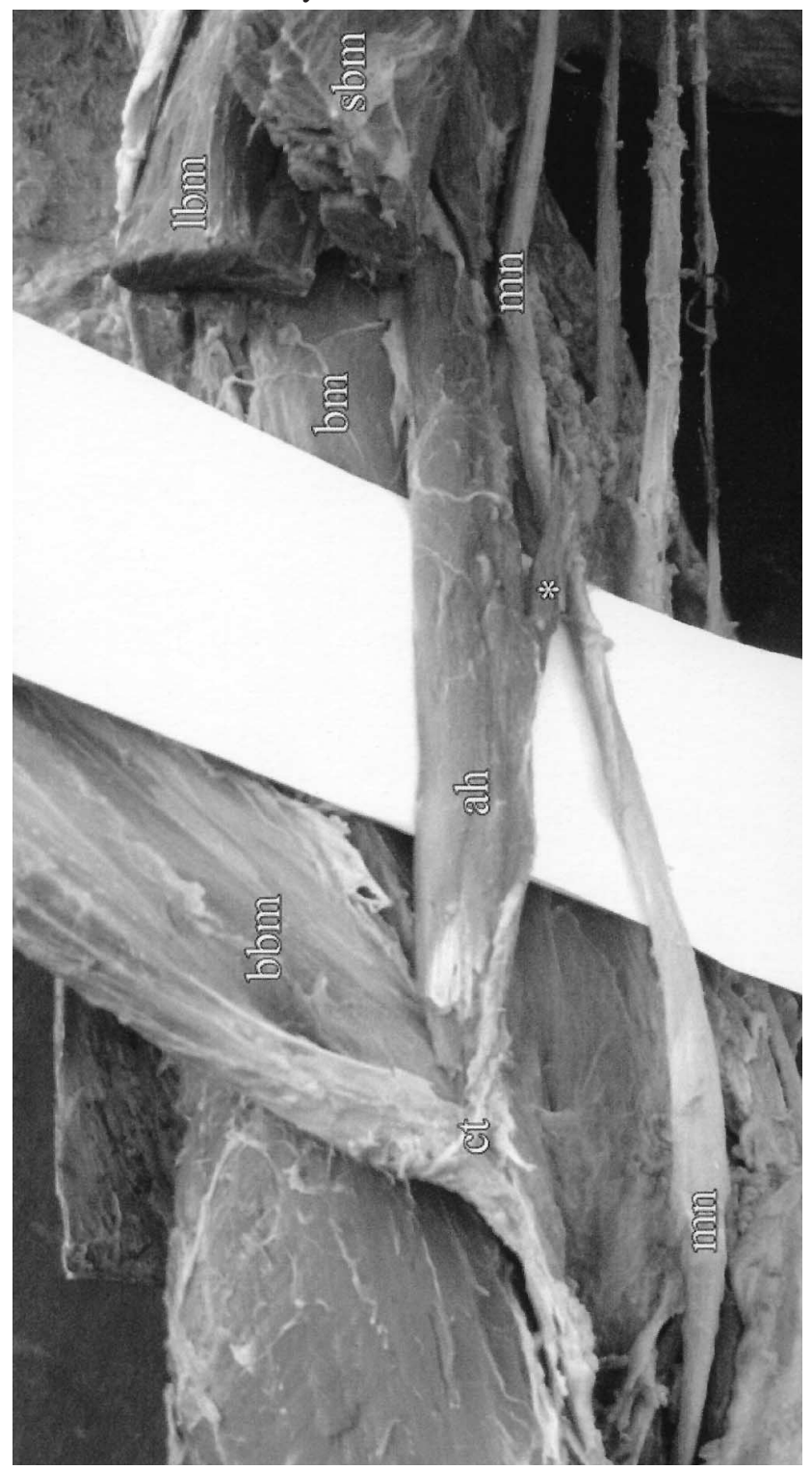

Fig. 2. Medial fibers of the accessory head of biceps brachii originating from the deep fascia of brachiais muscle and crossing over the median nerve. lbm: Long head of biceps brachii, sbm: Short head of biceps brachii, ah: Accessory head of biceps brachii, *: Medial fibers of the accessory head originating from the deep fascia of brachialis muscle, $\neq$ : Common tendon of biceps brachii, bbm: Biceps brachii muscle, bm: Brachialis muscle, mn: Median nerve. 


\section{DISCUSSION}

It is well known that the biceps brachii muscle variations are not rare (Asvat et al.; Rodriguez-Niedenführ et al.; Bergman et al., 1984; Greig et al., 1952; Tamura, 1971). Some authors emphasize that the most frequent variations of biceps brachii was in the number of the bellies (Bergman et al., 2000). Supernumerary heads of the biceps brachii have been described as part of three-, four-, five or even seven headed biceps brachii (Swieter \& Carmichael, 1980). However the three headed biceps brachii is the most commonly reported variation of the biceps brachii. It has been mentioned in the literature that the occasional presence of a third head varies according to the population from which the cadavers were sampled (Rodriguez-Niedenführ et al.). It has been stated that an accessory head had been observed in $8 \%$ of Chinese, $10 \%$ of European populations, $12 \%$ of African blacks, and \%18 of Japanese population (Bergman et al., 1984). A high incidence of the third head has also been reported in South African Blacks (20.5\%), but in the African Whites the incidence was only $8.3 \%$ (Asvat et al.). Though some of the authors claim that there were no clear racial differences, some of them mention significant differences between the populations (Asvat et al.; Bergman et al., 2000; Nakatani et al., 1998; Neto et al., 1998; ElNaggar \& Zahir, 2001).

From the data in the literature it has been concluded that in the white race the incidence of the accessory heads of the biceps brachii muscle was relatively rare, high in the yellow race and intermediate in Blacks (Khaledpour, 1985). On the other hand no significant differences in the prevalence of variations has been reported between male and females or between left and right sizes, but unilateral prevalence of the variation was significantly higher when compared with bilateral ones (Rodriguez-Niedenführ et al.). They have classified the accessory heads according to their location as superior, infero-medial, and infero-lateral humeral heads. The most commonly seen one was the infero-medial humeral head $(9 \%)$ in which the accessory head continuous with the insertion of the coracobrachialis muscle and closely related to medial intermuscular septum and brachialis muscle. A similar classification was also done (Asvat et al.). According to the authors the three principal origins of the accessory head of biceps brachii muscle were the humeral shaft inferior to and common with the insertion area for the coracobrachialis muscle, a brachial origin where the muscle originated distally from the medial humeral shaft, adjacent to and in common with the brachialis muscle or a dual origin where the medial fibers originated from the short head of biceps brachii muscle and the lateral fibers from the deltoid fascia and the insertion area of this muscle. In another study different from the above mentioned types. An accessory head has been reported arising from the distal part of the pectoralis major muscle (Sargon et al., 1996). Some investigators reported an accessory head that originates from the anterior surface of the humerus distal to the crest of the lesser tubercle and lay behind the long and short heads of biceps brachii as well (Swieter \& Carmichael). The accessory third head of biceps brachii observed in the present study mainly arises from the anteromedial surface of humeral shaft just lateral to the insertion of coracobrachialis as it was in the study by many authors (Asvat et al.; Rodriguez-Niedenführ et al.). It lies just between the bellies of biceps brachii and brachialis muscles and inserts into the posterior aspect of the common biceps tendon as mentioned by some authors (Swieter \& Carmichael), but the dual origin of the accessory head in the present study should be emphasized; a few fibers from the medial side of the accessory head arise from the fascia of brachialis muscle. Those fibers have been seen crossing the median nerve before inserting into the common tendon of biceps brachii. In other words the median nerve was piercing the accessory head before entering into the forearm.

Such variations are of importance for the anatomists. However a well informed clinician should also be aware of the major anatomical variations in muscles and the other organs even though the direct clinical significance of the variation may be minimal. An accessory head of biceps brachii muscle could cause an additional strength or an unusual displacement of humeral bone fragments subsequent to fracture (Swieter \& Carmichael). The accessory third head determined in al., the present variation probably would not cause an extra strength or an unusual displacement of the fragments. However construction of the muscle may cause compression on the median nerve since it passes between the fibers of the accessory head. So, information on such a variation is of importance for the differential diagnoses of the other compression causes such as enlarged veins (Braun \& Spinner, 1991) or a fibrovascular band (Holtzman et al., 1986). Biceps brachii is without doubt a considerable component in plastic surgery (Muneuchi et al., 2004; Willcox et al., 2002; Har-Shai et al., 1998) but it is known that accessory heads of biceps brachii would be expandable and possibly has more value in flap surgery rather than the two main heads. In the cases such as presented in this study the nerve or the vascular structure piercing the accessory head would probably cause difficulty during elevating or transferring the flaps.

These findings will also provide anatomic information, guidance and may support the literature and clinical contribution for reliable surgery. 
MAS, N.; PELIN, C.; ZAGYAPAN, R. \& BAHAR, H. Una rara relación del nervio mediano con la cabeza accesoria del músculo bíceps braquial. Un original reporte de caso. Int. J. Morphol., 24(4):561-564, 2006.

RESUMEN: Durante una disección de rutina de la región anterior del brazo, se observó una relación anormal del nervio mediano con una cabeza accesoria del músculo bíceps braquial, en un miembro superior derecho de un cadáver masculino. Mientras que las cabezas larga y corta tuvieron un origen normal, una tercera cabeza se originó de la superficie anteromedial de la parte superior del cuerpo humeral. Algunas fibras de esta cabeza accesorias, se originaron del lado medial de la fascia profunda que rodea al músculo braquial. Las fibras cruzaban al nervio mediano superficialmente, antes de unirse a la tercera cabeza, la cual se insertó a través de un tendón común con las cabezas larga y corta. El conocimiento de tales variaciones es de importancia tanto para anatomistas o clínicos, así como esencialmente para cirujanos plásticos en las cirugías, que se usan colgajos.

PALABRAS CLAVE: Músculo bíceps braquial; Cabeza accesoria; Nervio mediano; Variación anatómica.

\section{REFERENCES}

Asvat, R.; Candler, P. \& Sarmiento, E. E. High incidence of the third head of biceps brachii in South African populations. $J$. Anat. 182:101-4, 1993.

Bergman, R. A.; Afifi, A. K. \& Miyauchi, R. Part I: Muscular system. In: Ilustrated encyclopedia of human anatomic variation, 2000. http://www.vh.org./Providers/Textbooks/ AnatomicVariants/AnatomyHP.html.

Bergman, R. A.; Thompson, S. A. \& Afifi, A. K. Catalague of Human Variation. Munich: Urban and Schwarzenberg. 27-30, 1984.

Braun, R.M.; Spinner, R.J. Spontaneous bilateral median nerve compressions in the distal arm. J Hand Surg.16:244-7, 1991.

El-Naggar, M. M. \& Zahir, F. I. Two bellies of the coracobrachialis muscle associated with a third head of the biceps brachii muscle. Clin. Anat., 14:379-82, 2001.

Greig, H. W.; Anson, B. J. \& Budinger, J. M. Variations in the form and attachments of the biceps brachii muscle. Bull. Northwest Univ. Med Sch., 26:241-4, 1952.

Har-Shai, Y.; Kaufman, T.; Hasmonai, M.; Hirsowitz, B. \& Schramek, A. External longitudinal splitting of the biceps brachii muscle for coverage of repaired brachial vessels: an anatomical study and clinical application. 21:158-64, 1988.

Holtzman, R. N.; Patel, M. R. \& Mark, M. H. Median nevre neuralgia caused by a fibrovascular band in the distal forearm $J$. Hand Surg., 11:894-5, 1986.

Jakubowicz, M. \& Ratajczak, W. Variation in morphology of the biceps brachii and coracobrachialis muscles associated with abnormal course of blood vessels and nerves. Folia Morphol. (Warsz), 58: 255-8, 2000.

Khaledpour, C. Anomalies of the biceps muscle of the arm. Anat. Anz., 58:79-85, 1985.

Kosugi, K.; Shibata, S. \& Yamashita, H. Supernumerary head of biceps brachii and branching pattern of the musculocutaneous nerve in Japanese. Surg. Radiol. Anat., 14:175-85, 1992.
Muneuchi, D.; Suzuki, S.; Ito, O.; Saso, Y. One-stage reconstruction of both the biceps brachii and triceps brachii tendons using a free anterolateral thigh flap with a fascial flap. J. Reconstr. Microsurg., 20:139-42, 2004.

Nakatani, T.; Tanaka, S.; Mizukami, S. Bilateral four headed biceps brachii muscles: the median nerve and brachial artery passing through a tunnel formed by a muscle slip from the accessory head. Clin. Anat., 11:209-12, 1998.

Neto, H. S.; Camilli, J. A.; Andrade, J. C. T ; Filho, J. M. \& Marques, M. J. On the incidence of the biceps brachii third head in Brazilian whites and blacks. Ann. Anat., 180: 69-71, 1998.

Rodriguez-Niedenführ, N.; Vazquez, T.; Choi, D.; Parkin, I. \& Sanudo, J.S. Supernumerary humeral heads of the biceps brachii muscle revisited. Clin. Anat., 16:197-203, 2003.

Sargon, F. M.; Tuncali, D. \& Celik, H. An unusual origin for the accessory head of biceps brachii muscle. Clin Anat., 9:160-2, 1996.

Snell, R. S. Clinical Anatomy. $7^{\text {th }}$. ed. Lipincott Williams \& Wilkins, 2004.

Swieter, M. G. \& Carmichael, S.W. Bilateral three-headed biceps brachii muscles. Anat. Anz., 148:346-9, 1980.

Tamura, H. Case of the brachial biceps with two accessory heads in each. Kaibogaku Zasshi., 46:12-6, 1971.

Willcox, T. M.; Teotia, S. S.; Smith, A. A. \& Rawlings, J. M. The biceps brachii muscle flap for axillary wound coverage. Plast. Reconstr. Surg., 110:822-6, 2002.

Williams, P. L; Warwick, R.; Dyson, M; \&Bannister, L.H. Gray's Anatomy. $37^{\text {th }}$ ed. Edinburgh, Churchill Livingstone, 1989.

Correspondence to:
Dr. NuKet Mas
Baskent University
Faculty of Medicine
Department of Anatomy
06530 Bagfica--Etimesgut
Ankara TURKEY

e-mail: nmas@6askent.edu.tr 